\title{
Effect of Dental Wear, Stabilization Appliance and Anterior Tooth Reconstruction on Mandibular Movements During Speech
}

\author{
Priscila de Oliveira SERRANO \\ Fernanda FAOT \\ Altair Antoninha DEL BEL CURY \\ Renata Cunha Matheus RODRIGUES GARCIA \\ Department of Prosthodontics and Periodontology, Dental School of Piracicaba, \\ State University of Campinas, Piracicaba, SP, Brazil
}

\begin{abstract}
This study described changes in mandibular movements during pronunciation of $/ \mathrm{m} /$ and $/ \mathrm{s} /$ sounds in Portuguese, in patients presenting dental wear before and after appliance insertion and tooth reconstruction. Subjects were divided into a control group of dentate patients and an experimental group of patients with incisal tooth wear due to bruxism. A magnetic jaw tracking device measured the jaw opening, and translations to left and right sides of the mandible during pronunciation of phonemes. Evaluations were carried out 1 week and immediately before appliance insertion; 24 h, 7, 30 and 60 days after appliance insertion; and 1 week and 1 month after tooth reconstruction. Data were submitted to two-way ANOVA, Mann-Whitney and Friedman tests $(\mathrm{p}<0.05)$. Jaw opening was different $(p<0.05)$ for both sounds in all periods. The anteroposterior amplitude for /s/ showed differences immediately before and 1 month after appliance insertion ( $\mathrm{p}<0.05$ ). Lateral amplitude for the right side showed differences between groups after appliance insertion for /s/, and 1 and 2 months after appliance insertion for the $/ \mathrm{m} /(\mathrm{p}<0.05)$. Volunteers with anterior tooth wear had a wider opening movement, and the movements during speech of $/ \mathrm{m} /$ and $/ \mathrm{s} /$ sounds were not changed after appliance insertion and reconstruction of teeth.
\end{abstract}

Key Words: tooth wear, stabilization appliances, speech.

\section{INTRODUCTION}

The articulation of sounds depends on the presence and position of teeth, and dental occlusion (1), in order to enable the points of contact and the restriction of air flow associated with the movements of the tongue, lips and cheeks (2). The precision of speech articulation is related to the freedom of the mandibular movements, modifying the spaces in order to allow the different articulatory positions of each sound (2). Furthermore, analysis of the mandibular movements during speech has been a useful method for determining the vertical dimension of dental occlusion, anterior guideline and tooth position in the rehabilitation treatment of patients (3). Mandibular movement dimensions are also important variables in the evaluation of speech patterns (4). They are highly coordinated and do not involve dental contact (3).

A variety of phonetic exercises has been used to study mandibular movement during speech (5). Mandibular positions have been observed for single words $(6,7)$, during and after counting and in the phonation of short phrases (7). The most frequently used phonemes for mandibular movement studies are the sibilants (8) and the nasals (9). The production of the /s/ sound requires very precise placement of the articulators, such as tongue position and a narrow stream of air across the incisal edges (10). Moreover, sibilant sounds are the ones most frequently affected by dental and skeletal jaw abnormalities (11).

Bruxism has been found to be the decisive factor in dental attrition affecting the degree of tooth damage 
(12), and contributing to the progression of wear (13). It can lead to an excessive reduction of clinical crown height (12) and often requires restorative intervention (14). The therapy for patients with bruxism should include reversible and non-invasive methods (12), such as insertion of stabilization appliances, which are the most widely accepted form of treatment (15).

Stabilization appliances are designed to provide joint stabilization, protect the teeth, relax the elevator muscles and redistribute the forces (16). Considering that masseter and temporal muscles are in activity during speech (17), and their electromyographic activity is reduced after insertion of stabilization appliances (18), it may be hypothesized that insertion of stabilization appliance could affect the mandibular movements during speech. Moreover, patients with tooth wear due to bruxism may have the function and shape of their teeth reestablished (14) and the restorative treatment should be conservative, not demanding further reduction of tooth structure. The treatment of localized anterior tooth wear with resin-based composite restorations offers a practicable option. The reversible nature of this approach may allow future treatment alternatives.

Although previous studies have investigated the effect of tooth wear on oral functions $(14,19)$, there is no knowledge of the effect of stabilization appliances and anterior tooth reconstruction on mandibular movements during speech, as regards sibilant and nasal sounds.

The purpose of this study was to analyze, by means of the magnetic jaw-tracking method, the effect of dental wear, stabilization appliance therapy and incisal tooth reconstruction on mandibular movements during speech of $/ \mathrm{m} /$ and $/ \mathrm{s} /$ sounds in the Portuguese language. This investigation was conducted with volunteers that had experienced tooth wear due to bruxism, had used a joint stabilization appliance and had had their anterior teeth reconstructed.

\section{MATERIAL AND METHODS}

Thirty-seven volunteers took part in this study and were assigned to two groups. Only healthy subjects without systemic disease were enrolled. No subject suffered from any speech or hearing disorders or had a history or symptoms of temporomandibular dysfunction.

The control group comprised 16 female and 3 male undergraduate dental students and employees of the Dental School of Piracicaba, University of Campinas, Brazil ( mean age $=23$ years; range $=16$ to 27 years). All individuals had complete dentition with at least 24 teeth, no occlusal vertical dimension (OVD) alterations, no malocclusion and no previous use of any occlusal appliance.

The experimental group consisted of 6 women and 12 men selected from patients treated at the Dental Clinic of the Dental School of Piracicaba and from undergraduate students of the Luiz de Queiroz Agriculture School, University of São Paulo, Piracicaba, Brazil ( mean age $=33$ years; range $=21$ to 63 years ) . Experimental subjects were also selected from 3 High Schools at the ciy of Piracicaba (State School Monsenhor Jerônimo Gallo, State School Professor Antonio José Falcone and State School Doctor Prudente). In addition to the criteria described for the control group, a prerequisite of the experimental group was that every subject should have anterior dental wear due to bruxism. Since there is no difference in speech envelope dimensions between men and women (5) there was no concern about this parameter during selection of the study subjects.

Bruxism was clinically diagnosed based on the presence of tooth wear on the anterior teeth and by tooth grinding or clenching sounds noticed by the patient sleep partner or a family member (20). Abnormal wearing facets of the teeth should present score 2 (wear into the dentine; dentine exposed incisally or adjacent to the tooth surface with incisal morphology changed in shape, and with reduced crown height) in accordance with the ordinal scale of wear severity (14). The local Research Ethics Committee independently reviewed and approved the study protocol and all subjects signed an informed consent form for participation.

The group presenting tooth wear received a fullarch maxillary joint stabilization appliance and restorative treatment of the anterior teeth. All appliances were made on accurate dental casts mounted on an adjustable articulator at maximum intercuspal position. They were waxed with 1.5 to $2 \mathrm{~mm}$ thickness in the posterior area and prepared with acrylic resin. The appliances were fitted in the volunteers' mouths and balanced at the centric stops and in the intercuspal position. Subjects were instructed to use the appliance primarily at night and, after 60 days of appliance use, they had the worn anterior teeth restored.

Restorative treatment performed at the chairside involved a direct, freehand build-up of composite resin. 
The teeth were etched with $37 \%$ phosphoric acid (Scotchbond; 3M/ESPE, St. Paul, MN, USA) for $15 \mathrm{~s}$, rinsed, blotted dry with a moist cotton pellet and Single Bond adhesive system (3M/ESPE) was applied to enamel and air-thinned for $10 \mathrm{~s}$. The worn teeth were reshaped with direct composite resin (Charisma; Heraeus Kulzer GmbH, Wehrheim, Germany; and Filtek Z-250; 3M/ ESPE) in order to restore the original contour. Finishing of composite restorations was carried out conventionally with Soflex disks (3M Healthcare, Loughborough, UK) and polishing points (Enhance; Dentsply, Weybridge, UK). New joint stabilization appliances were made for subjects after restorative treatment.

Magnetic jaw tracking equipment (KinesiographK6 - I Diagnostic System; Myotronics-Noromed, Kent, WA, USA) was used to record mandibular movements during speech. The sirognathograph headset was mounted and aligned with the subject seated upright on a dental chair, with the head firmly supported and the Frankfort horizontal plane parallel to the floor. The magnet was attached to the labial vestibule, just below the mandibular incisors. Subjects were instructed to keep their heads as steady as possible during recording. The speech test was performed for pronunciation and rate and volume of speech. Subjects were asked to close to the maximum intercuspal position; and to speak the phoneme $/ \mathrm{m} /$ in Portuguese 10 times, until the equipment provided the mandibular movements during speech. The subject started and finished each test at the referent point (maximum intercuspal position). The same procedure was carried out to record the mandibular movements for the /s/ sound. All recordings were made with no appliance in the mouth.

Data referring to the mandibular movements during the pronunciation of the $/ \mathrm{m} /$ and $/ \mathrm{s} /$ sounds in the Portuguese language were quantified according to: maximum opening amplitude in the sagittal plane $(\mathrm{mm})$; maximum anterior-posterior amplitude $(\mathrm{mm})$; maximum amplitude of lateral translations $(\mathrm{mm})$ to the right and to the left sides. The speech exercise was recorded 3 times for each subject in order to give a mean value.

The mandibular movements during speech were determined for the experimental group, which received the joint stabilization appliance and restorative treatment, in the following periods: 7 days before and immediately before appliance insertion; $24 \mathrm{~h}$ after appliance insertion; 7 days after; 1 month after; 2 months after appliance insertion; 7 days and 1 month after restorative treatment. Subjects from control group were assessed in the same periods of time. All recordings were made with no appliance in the mouth.

\section{Statistical Analysis}

The assumptions of equality of variances and normal distribution of errors were checked for all the response variables tested in the study. Data with homogeneous variances were analyzed by two-way ANOVA, and those with non homogeneous variances were analyzed using a nonparametric test. Two-way ANOVA was used to compare means of maximum opening amplitude for $/ \mathrm{m} /$ and $/ \mathrm{s} /$ sounds between groups, and also to compare the mean values of maximum opening amplitude before appliance insertion and after subsequent consecutive periods, following appliance insertion and restorative treatment.

Values from control and experimental groups for maximum anteroposterior amplitude and for maximum amplitude of lateral translations to the right and to the left sides, measurements recorded for $/ \mathrm{m} /$ and $/ \mathrm{s} /$ sounds, were compared by the Mann-Whitney test. The values before appliance insertion and subsequent appliance insertion and restorative treatment periods, for maximum anteroposterior amplitude and maximum amplitude of lateral translations to right and left sides, were compared using the Friedman test. Significance level for all analyses was set at $5 \%$.

\section{RESULTS}

The two-way ANOVA results for maximum opening amplitude for $/ \mathrm{m} /$ and $/ \mathrm{s} /$ sounds are presented in Table 1 . The mean maximum opening amplitude obtained during pronunciation of the $/ \mathrm{m} /$ sound ranged from $12.34 \mathrm{~mm}$ to $12.80 \mathrm{~mm}$ for the experimental group, and from $9.43 \mathrm{~mm}$ to $9.80 \mathrm{~mm}$ for the control group. During pronunciation of the /s/ sound, the mean maximum opening amplitude ranged from $12.72 \mathrm{~mm}$ to $13.67 \mathrm{~mm}$ for the experimental group and from 10.46 $\mathrm{mm}$ to $11.00 \mathrm{~mm}$ for the control group (Table 2).

There was statistically significant difference $(p<0.05)$ for these values between groups in all test periods. The experimental group showed higher values. The mean maximum opening amplitude was not significantly altered by insertion of the stabilization appliance, or the restorative treatment (Table 2). 
Table 3 shows that the maximum anteroposterior amplitude measurements recorded for the /s/ sound differed significantly $(\mathrm{p}<0.05)$ between groups before appliance insertion and 30 days after appliance insertion. There was statistically significant difference $(\mathrm{p}<0.05)$ between groups for the mean maximum amplitude of

Table 1. Two-way ANOVA for maximum opening amplitude during speech of the $/ \mathrm{m} / \mathrm{and} / \mathrm{s} /$ sounds.

\begin{tabular}{|c|c|c|c|c|c|c|c|c|c|}
\hline & \multicolumn{5}{|c|}{$/ \mathrm{m} /$ sound } & \multicolumn{4}{|c|}{ /s/ sound } \\
\hline & df & Sum of squares & Mean square & $\mathrm{F}$ & $P$ & Sum of squares & Mean square & $\mathrm{F}$ & $P$ \\
\hline Treatments & 50 & 68.01 & 1.36 & 97.19 & $<.0001$ & 55.05 & 1.10 & 64.77 & $<.0001$ \\
\hline Within & 245 & 3.43 & 0.01 & & & 4.16 & 0.02 & & \\
\hline Total & 295 & 71.53 & & & & 59.22 & & & \\
\hline
\end{tabular}

Table 2. Maximum opening amplitude obtained during pronunciation of $/ \mathrm{m} / \mathrm{and} / \mathrm{s} /$ sounds before and after joint stabilization appliance insertion and after restorative treatment.

\begin{tabular}{lccccc}
\hline \multirow{2}{*}{ Time } & \multicolumn{2}{c}{$/ \mathrm{m}$ / sound } & & \multicolumn{2}{c}{ /s/ sound } \\
\cline { 2 - 3 } & $\begin{array}{c}\text { Control } \\
\text { group }(\mathrm{n}=19)\end{array}$ & $\begin{array}{c}\text { Experimental } \\
\text { group }(\mathrm{n}=18)\end{array}$ & & $\begin{array}{c}\text { Control } \\
\text { group }(\mathrm{n}=19)\end{array}$ & $\begin{array}{c}\text { Experimental } \\
\text { group }(\mathrm{n}=18)\end{array}$ \\
\hline 1 week before splint placement & $9.56(2.49)$ & $12.34(4.07)^{*}$ & & $10.86(1.61)$ & $12.97(3.74)^{*}$ \\
Immediately before & $9.43(2.45)$ & $12.55(3.62)^{*}$ & & $10.46(1.70)$ & $12.72(3.92)^{*}$ \\
24 h after & $9.60(2.46)$ & $12.51(3.94)^{*}$ & & $10.83(1.84)$ & $13.18(4.14)^{*}$ \\
7 days after & $9.68(2.11)$ & $12.37(3.85)^{*}$ & & $10.68(2.07)$ & $13.16(3.67)^{*}$ \\
30 days after & $9.96(2.57)$ & $12.52(3.64)^{*}$ & & $10.74(1.79)$ & $13.52(4.00)^{*}$ \\
60 days after & $9.79(2.27)$ & $12.64(3.69)^{*}$ & & $10.85(2.04)$ & $13.67(4.12)^{*}$ \\
1 week after oral rehabilitation & $9.80(2.55)$ & $12.80(3.53)^{*}$ & & $10.97(1.68)$ & $13.40(3.73)^{*}$ \\
1 month after oral rehabilitation & $9.76(2.24)$ & $12.57(3.18)^{*}$ & & $11.00(1.94)$ & $13.18(3.55)^{*}$ \\
\hline
\end{tabular}

*Differed from control group by ANOVA ( $\mathrm{p}<0.05)$. Values are expressed in mm as means (SD).

Table 3. Maximum anteroposterior amplitude obtained during pronunciation of $/ \mathrm{m} / \mathrm{and} / \mathrm{s} / \mathrm{sounds}$ before and after joint stabilization appliance insertion and after restorative treatment.

\begin{tabular}{lccccc}
\hline Time & \multicolumn{2}{c}{$/ \mathrm{m}$ / sound } & & \multicolumn{2}{c}{ /s/ sound } \\
\cline { 2 - 3 } & $\begin{array}{c}\text { Control } \\
\text { group (n=19) }\end{array}$ & $\begin{array}{c}\text { Experimental } \\
\text { group (n=18) }\end{array}$ & & $\begin{array}{c}\text { Control } \\
\text { group (n=19) }\end{array}$ & $\begin{array}{c}\text { Experimental } \\
\text { group (n=18) }\end{array}$ \\
\hline 1 week before splint placement & $3.46(1.47)$ & $2.74(1.80)$ & & $3.36(1.56)$ & $2.73(1.47)^{*}$ \\
Immediately before & $3.36(1.68)$ & $2.64(1.31)$ & & $3.16(1.74)$ & $2.6(1.50)^{*}$ \\
24 h after & $3.36(1.70)$ & $2.73(1.36)$ & & $3.24(1.44)$ & $2.74(1.51)$ \\
7days after & $3.48(1.41)$ & $2.68(1.45)$ & & $3.18(1.40)$ & $2.59(1.42)$ \\
30 days after & $3.47(1.86)$ & $2.71(1.40)$ & & $3.63(1.46)$ & $2.72(1.37)^{*}$ \\
60 days after & $3.14(1.65)$ & $2.53(1.54)$ & & $3.07(1.83)$ & $2.79(1.66)$ \\
1 week after oral rehabilitation & $3.44(1.76)$ & $3.32(1.67)$ & & $3.18(1.56)$ & $3.34(1.73)$ \\
1 month after oral rehabilitation & $3.14(1.33)$ & $3.00(1.74)$ & & $3.13(1.56)$ & $2.84(1.53)$ \\
\hline
\end{tabular}

*Differed from control group by Mann Whitney test $(\mathrm{p}<0.05)$. Values are expressed in mm as means (SD). 
lateral translations to the right side in the periods following appliance insertion, during pronunciation of the /s/ sound (Table 4) and at 30 and 60 days after appliance insertion, during pronunciation of the $/ \mathrm{m} /$ sound (Table 5). The mean maximum amplitude of lateral translations to the left side during $/ \mathrm{m} /$ sound pronunciation showed statistical difference $(\mathrm{p}<0.05)$ for the experimental group before appliance insertion and after one week of restorative treatment (Table 5).

\section{DISCUSSION}

The present study used a jaw tracking method to evaluate mandibular movements occurring in patients with dental wear before and after occlusal appliance insertion and reconstruction of anterior teeth. It was observed that the presence of anterior tooth wear could change mandibular movements during the pronunciation of the $/ \mathrm{s} /$ and $/ \mathrm{m} /$ sounds of the Portuguese language.

Table 4. Maximum amplitude of lateral translations to right and left sides obtained during pronunciation of the /s/ sound before and after joint stabilization appliance insertion and after restorative treatment.

\begin{tabular}{lccccc}
\hline \multirow{2}{*}{ Time } & \multicolumn{2}{c}{ Right side } & & \multicolumn{2}{c}{ Left side } \\
\cline { 2 - 3 } & $\begin{array}{c}\text { Control } \\
\text { group }(\mathrm{n}=19)\end{array}$ & $\begin{array}{c}\text { Experimental } \\
\text { group }(\mathrm{n}=18)\end{array}$ & & $\begin{array}{c}\text { Control } \\
\text { group }(\mathrm{n}=19)\end{array}$ & $\begin{array}{c}\text { Experimental } \\
\text { group (n=18) }\end{array}$ \\
\hline 1 week before splint placement & $0.87(0.71)$ & $1.37(1.02)$ & & $1.37(0.77)$ & $1.59(0.95)$ \\
Immediately before & $0.79(0.67)$ & $1.20(0.79)$ & & $1.25(0.74)$ & $1.64(0.87)$ \\
24 h after & $0.53(0.58)$ & $1.25(0.80)^{*}$ & & $1.54(0.72)$ & $1.67(1.13)$ \\
7days after & $0.72(0.51)$ & $1.17(0.75)^{*}$ & & $1.65(0.99)$ & $1.71(1.07)$ \\
30 days after & $0.64(0.51)$ & $1.11(0.81)^{*}$ & & $2.10(2.12)$ & $1.63(0.99)$ \\
60 days after & $0.47(0.45)$ & $1.15(0.84)^{*}$ & & $1.76(0.80)$ & $1.49(1.02)$ \\
1 week after oral rehabilitation & $0.63(0.68)$ & $1.05(0.83)$ & & $1.50(0.71)$ & $1.96(1.57)$ \\
1 month after oral rehabilitation & $0.53(0.40)$ & $0.96(0.83)$ & & $1.70(0.80)$ & $1.74(0.94)$
\end{tabular}

*Differed from control group by Mann Whitney test $(\mathrm{p}<0.05)$. Values are expressed in mm as means (SD).

Table 5. Maximum amplitude of lateral translations to right and left side obtained during pronunciation of the $/ \mathrm{m} /$ sound before and after joint stabilization appliance insertion and after restorative treatment.

\begin{tabular}{|c|c|c|c|c|}
\hline \multirow[t]{2}{*}{ Time } & \multicolumn{2}{|c|}{ Right side } & \multicolumn{2}{|c|}{ Left side } \\
\hline & $\begin{array}{c}\text { Control } \\
\text { group }(n=19)\end{array}$ & $\begin{array}{l}\text { Experimental } \\
\text { group }(n=18)\end{array}$ & $\begin{array}{c}\text { Control } \\
\text { group }(n=19)\end{array}$ & $\begin{array}{l}\text { Experimental } \\
\text { group }(\mathrm{n}=18)\end{array}$ \\
\hline 1 week before splint placement & $0.44(0.29)$ & $0.83(0.64)$ & $1.13(0.72)$ & $1.21(1.19)$ \\
\hline Immediately before & $0.64(0.60)$ & $1.06(0.98)$ & $1.06(0.94)$ & $1.24(0.92)$ \\
\hline $24 \mathrm{~h}$ after & $0.56(0.53)$ & $0.82(0.54)$ & $1.23(0.61)$ & $1.58(1.05)$ \\
\hline 7days after & $0.55(0.52)$ & $0.93(0.69)$ & $1.34(0.80)$ & $1.50(1.15)$ \\
\hline 30 days after & $0.40(0.43)$ & $1.08(0.97)^{*}$ & $1.33(0.84)$ & $1.25(0.70)$ \\
\hline 60 days after & $0.28(0.28)$ & $0.78(0.60)^{*}$ & $1.57(0.69)$ & $1.36(0.82)$ \\
\hline 1 week after oral rehabilitation & $0.52(0.56)$ & $0.59(0.60)$ & $1.50(0.72)$ & $1.86(1.28) \dagger$ \\
\hline 1 month after oral rehabilitation & $0.63(0.66)$ & $0.83(0.75)$ & $1.25(0.63)$ & $1.48(0.75)$ \\
\hline
\end{tabular}

*Differed from control group by Mann Whitney test $(\mathrm{p}<0.05) . \dagger$ Differed from before appliance installation by Friedman test $(\mathrm{p}<0.05)$. 
There was a significant difference between the control and experimental groups for the mean maximum opening amplitude during pronunciation of the $/ \mathrm{m} /$ and /s/ sounds. These results disagree with those of previous studies $(14,19)$. Ishigaki et al. (19) evaluated the initial and the maximal opening and closing mandibular movements in volunteers with bruxism and temporomandibular disorder, and no differences were found in the average values of initial and maximal opening between control and experimental subjects. Given that the present experiment measured the maximum opening during speech, these disagreements may be explained by the different methodologies used in both studies.

The mandibular envelope of motion during speech in subjects with and without tooth wear was also studied by Burnett and Clifford (14), who reported lower values for the vertical envelope dimensions in the tooth wear group. In the present study, on the other hand, higher values were found. In order to measure the mandibular envelope during speech, those authors (14) used a passage containing all phonemes that occur in the English language. In contrast, the present study evaluated the maximal opening movements during speech of only two phonemes from the Portuguese language. Therefore, the different results may be attributed to the different sounds evaluated and languages spoken. In addition, the amount of tooth wear may also be a contributing factor. Burnett and Clifford (14) evaluated subjects with a reduction of more than one third of the original height of the maxillary incisors, with an edge-toedge incisal relationship. These volunteers probably had an altered VDO and muscular involvement. In the present study, however, the subjects presented only anterior tooth wear.

Speech sound production not only requires the jaw to move freely, but also need an intact nervous system and sufficient dental and alveolar structures (2). Volunteers with anterior tooth wear due to bruxism probably could have compensatory changes in tongue and mandibular positions, as the form of a speech sound articulator changes, as for example, with wear of the anterior teeth (14).

The mean maximum opening amplitude during pronunciation of $/ \mathrm{s} /$ and $/ \mathrm{m} /$ sounds was not significantly different before and after stabilization appliance insertion (Table 2). According to McFarland et al. (1), this could be due to the fact that during functional modifications (e.g.: insertion of an oral device), an immediate speech compensation and a potential contribution of sensory information in the adaptive process may occur.

Stabilization appliance therapy is beneficial to the stomatognathic system. It can provide stable muscular and articular positions, block the mechanism that modifies neuromuscular functions, which decreases the electromyographic activities of masticatory muscles (15). Indeed, the stabilization appliance could have a different effect on mandibular movements during speech if its use was evaluated for a longer period of time.

Structural disturbances, such as in teeth, can introduce changes to the vocal tract, which do not directly avoid speech articulation (1). With regard to the restorative treatment involving a direct build-up of composite resin, there is no evidence of the experimental group adapting to the changes in the height of the anterior teeth. Changes of other articulators, such as tongue and mandible position, might have already occurred $(7,14)$. According to Burnett $(7)$, speech sounds are articulated and modified by a variety of oral organs and structures, among with the mandible, and speech adaptability must be taken into account when interpreting mandibular positional formats. Speakers have a mental representation of the supralaryngeal vocal tract that they use to produce a particular speech sound. Deviations from normal intraoral conditions produce appropriate movements to rearrange the vocal tract shape in compensation.

When the groups were compared, the maximum anteroposterior amplitude measurements, recorded for the /s/ sound, were significantly different $(\mathrm{p}<0.05)$ before appliance insertion and 30 days after appliance insertion. This movement must have been influenced by the anterior tooth wear, considering that the emission of /s/ sounds depends on the minimum of interincisal separation and consequently the relationship of upper and lower teeth (6,9-10). Moreover, sibilant sounds produce the mandibular position that comes closest to the maximum intercuspal position during speech (7).

The mean maximum amplitude of lateral translations to the right side during pronunciation of $/ \mathrm{s} /$ and / $\mathrm{m} /$ sounds showed significant difference $(\mathrm{p}<0.05)$ between groups (Tables 4 and 5) after stabilization appliance insertion. The flat, smooth surface of the stabilization appliance could have promoted extensive amplitude to mandibular movements and when accentuated deviations in mandibular movements are seen, this can be 
indicative of structural or functional interferences (2). According to Ishigaki et al. (19), it is also possible to have asymmetric movements of the right and left articular condyles.

The mean maximum amplitude of lateral translations to the left side during pronunciation of the $/ \mathrm{m} /$ sound showed statistically significant difference $(\mathrm{p}<0.05)$ for the experimental group before appliance insertion and after one week of restorative treatment (Table 5). When disocclusion guidance was restored, this could have promoted deviations in mandibular movement that were not observed after 1 month of evaluation.

The mandibular movement values obtained for the control group during pronunciation of $/ \mathrm{m} /$ and $/ \mathrm{s} /$ sounds (Tables 2-5) were lower than those reported in previous investigations $(2,14)$. In the present study, sound emission was evaluated separately, while in the other studies, sounds were placed in words or sentences, which could contribute to the difference in the obtained results.

In this study, the mean age of control and experimental subjects was different approximately 10 years. In addition, patients received two treatments: insertion of a joint stabilization appliance and restorative treatment of the anterior teeth. These could, therefore, be considered as a limitation of this study because of the combined effect. Furthermore, some factors can affect the speech mandibular envelope, such as age and gender, which provide variations in speech articulation (14). Only few studies have recorded jaw movement parameters as measures of oral motor function specifically in relation to age (4), and it was concluded that age rather than the state of dentition is related to a reduction in some aspects of oral motor function. However, it is important to emphasize that in the above-mentioned study, the mean age of subjects was 80 , whereas in the present study it was less than half of that. Although the mean age of control and experimental groups of the present study was different (23 and 33 years, respectively), subjects' motor functions did not seem to be affected by age, compared to a previous study (4).

In summary, patients that had experienced anterior tooth wear due to bruxism, had used a stabilization appliance and had the incisal teeth reconstructed showed wider maximum opening amplitude during speech of / $\mathrm{m} / \mathrm{and} / \mathrm{s} /$ sounds in the Portuguese language. The appliance therapy and reconstruction of anterior teeth did not modify the mandibular movements during speech.

\section{RESUMO}

O objetivo deste estudo foi verificar alterações nos movimentos mandibulares durante a pronúncia dos fonemas $/ \mathrm{m} / \mathrm{e} / \mathrm{s} / \mathrm{da}$ língua portuguesa, em pacientes com desgaste dental incisal antes a após a instalação de placas interoclusais e restauração dos dentes. Os voluntários foram divididos em grupo controle, composto por pacientes dentados, e grupo experimental composto por pacientes com desgastes incisais devido ao bruxismo. Desvios laterais para direita e esquerda, e de abertura foram mensurados por meio do método eletromagnético do registro do traçado mandibular durante a pronúncia dos fonemas $/ \mathrm{m} / \mathrm{e} / \mathrm{s} /$. As avaliações foram realizadas 1 semana e imediatamente antes da instalação de placas interoclusais; 24 h, 7, 30 e 60 dias após a instalação das mesmas, e 1 semana e 1 mês após a restauração dos dentes. Os resultados foram submetidos à ANOVA a dois critérios e testes de Mann-Whitney e Friedman $t(\mathrm{p}<0,05)$. O movimento de abertura foi diferente $(\mathrm{p}<0,05)$ para ambos os sons em todos os períodos avaliados. Houve diferença $(\mathrm{p}<0,05)$ na amplitude anteroposterior durante pronúncia do som $/ \mathrm{s} /$ imediatamente antes e 1 mês após a instalação da placa. $O$ desvio lateral para o lado direito apresentou diferença $(\mathrm{p}<0,05)$ entre grupos durante a pronúncia do /s/ em todos os períodos após a inserção da placa, e 1 mês e 2 meses após a inserção da mesma para o som $/ \mathrm{m} /$. Pacientes com desgaste dental anterior apresentaram amplo movimento de abertura, e movimentos mandibulares durante a pronúncia dos sons $/ \mathrm{m} / \mathrm{e} / \mathrm{s} /$ não foram alterados após a instalação de placa e restauração dos dentes.

\section{REFERENCES}

1. McFarland DH, Baum SR, Chabot C. Speech compensation of structural modifications of the oral cavity. J Acoust Soc Am 1996;100:1093-1104.

2. Bianchini EMG, Andrade CRF. A model of mandibular movements during speech: normative pilot study for the Brazilian Portuguese language. Cranio 2006;24:197-206.

3. Meier B, Luck O, Harzer W. Interocclusal clearance during speech and in mandibular rest position. J Orofac Orthop 2003;64:121-134

4. Karlsson S, Carlsson GE. Characteristics of mandibular masticatory movement in young and elderly dentate subjects. J Dent Res 1990;9:473-476.

5. Burnett CA. Reproducibility of the speech envelope and interocclusal dimensions in dentate subjects. Int J Prosthodont 1994; 7:543-548.

6. Burnett CA, Clifford TJ. Closest speaking space during the production of sibilant sounds and its value in establishing the vertical dimension of occlusion. J Dent Res 1993;72:964967.

7. Burnett CA. Mandibular incisor position for English consonant sounds. Int J Prosthodont 1999;3:263-271.

8. Lu GH, Chow TW, So LKH, Clark RKF. A computer-aided study of speaking spaces. J Dent Res 1993;21:289-296.

9. Mehringer EJ. The use of speech patterns as an aid in prosthodontic reconstruction. J Prosthet Dent 1963;13:825837.

10. Vallino LD, Tompson B. Perceptual characteristics of consonant errors associated with malocclusion. J Oral Maxillofac Surg 1993;51:850-856. 
11. Garber SR, Speidel TM, Marse G. The effects on speech of surgical premaxillary osteotomy. Am J Orthod1981;79:5462.

12. Yip KHK. Rehabilitating a patient with bruxism-associated tooth tissue loss: a literature review and case report. Gen Dent 2003;51:70-74.

13. Johansson A, Haraldson T, Omar R, Kiliaridis S, Carlsson GE. A system for assessing the severity and progression of oclusal tooth wear. J Oral Rehabil 1993;20:125-131.

14. Burnett CA, Clifford TJ. The mandibular speech envelope in subjects with and without incisal tooth wear. Int J Prosthodont 1999;12:514-518.

15. Sheikholeslam A, Holmgren K, Riise C. A clinical and electromyographic study of the long-term effects of an occlusal splint on the temporal and masseter muscles in patients with parafunctional disorders and nocturnal bruxism. J Oral Rehabil 1986;13:137-145.
16. McNeill C. Temporomandibular disorders: guidelines for evaluation, diagnosis and management. 2nd ed. Chicago: Quintessence Publishing Co; 1990. p. 90.

17. Smith A. Speech motor development: integrating muscles, movements, and linguistic units. J Commun Disord 2006;39:331-349.

18. Williamson EH, Lundquist DO. Anterior guidance: its effect on electromyographic activity of the temporal and masseter muscles. J Prosthet Dent 1983;49:816-823.

19. Ishigaki S, Nakamura T, Akanishi M. Maruyama T. Clinical classification of maximal opening and closing movements. Int J Prosthodont 1989;2:148-154.

20. American Sleep Disorders Association. Parasomnia: International classification of sleep disorders: diagnostic and coding manual. Thorpy, MJ. Editor: Rochester, MN: ASDA, 1990;142-185. 